will be a multicentred special supervision service. One of the centres (probably at the postgraduate teaching hospital) will be a small inpatient unit giving a regional service for assessment of difficult patients, treatment of specially referred problems, consultation, teaching, and research. Each health area is joining the arrangements with a supervision service for its own patients providing both inpatient and outpatient facilities.

The Government has asked us not to concern ourselves with psychopaths, as the Butler Committee recommended prison developments for them. Our scheme will deal primarily with the mentally ill and it will provide flexible graded supervision all the way from maximum security to outpatient care in four tiers. Tier 1 exists already in the form of the special hospitals; we will provide tier 2 (the regional unit) and tiers 3 and 4 (the area arrangements). On 16 September we issued a publicity document "Secure but not Secured" setting out the proposal for the layman. I would be happy to let anyone have a copy; alternatively they could write to SETRHA at Randolph House, Wellesley Road, Croydon.

Finally, I would like to endorse the plea made by Dr Price for different regions to try different approaches to the problems confronting them. A uniform blueprint for the whole country is fine if it is the correct solution, but what if it is wrong ? A variety of approaches introduced gradually will surely give us the best opportunity of maximising our experience. It will be interesting to see if the DHSS wil approve the SETRHA scheme, which is distinctly different from other proposals they have already approved.

Special Hospitals Research Unit, Institute of Psychiatry, London SE5

\section{Epidural analgesia in labour}

SIR,-In 1970 a letter from this department reported no effects from epidural analgesia on the rates of either caesarean section or combined forceps and ventouse deliveries during the years $1965-9$. In the middle of 1969 $20 \%$ of patients were receiving epidural analgesia in labour.

Since 1969 there has been an obvious change in the incidence of operative vaginal delivery and this can be readily seen in the accompanying figure. Ventouse-assisted deliveries account for less than $1 \%$ of cases in this unit.

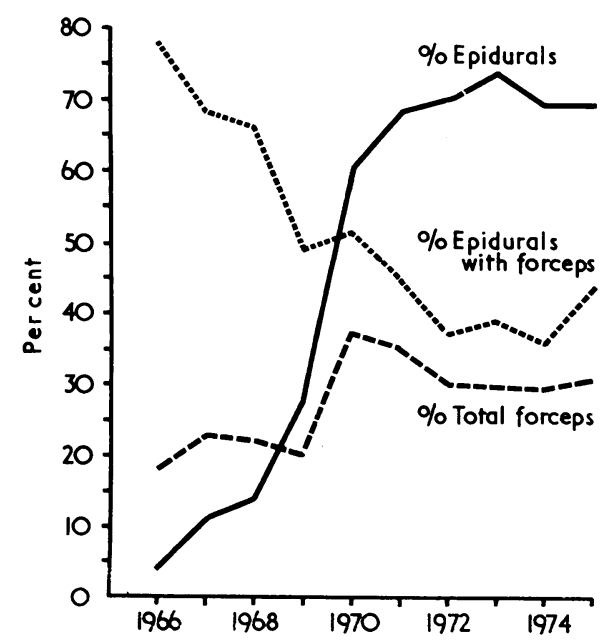

During the last decade it can be seen that the forceps delivery rate increased sharply as the use of epidural analgesia changed from $20 \%$ to $40 \%$ of women. The only other policy change in the unit during these 10 years has been an increase in induced labour, but this has been a gradual change from $20.2 \%$ in 1966 to $39.2 \%$ in 1975 .

The total forceps rate has fallen from $36 \%$ to $30 \%$ since 1970 and this is probably due to a better understanding of second-stage management when this form of analgesia is used. In $197435.0 \%$ of patients with epidurals had forceps deliveries and the total forceps rate for all patients was $28.5 \%$. These would appear to be fairly typical figures for units using epidural analgesia as their main form of pain relief in labour.

David P L MAY R D DE VERE

\section{Department of Obstetrics and \\ Gynaecology, \\ Westminster Hospital,}

London SW1 'Noble, A D, and de Vere, R D, British Medical fournal,
1970, 2, 296.

\section{Thyrotoxic vomiting}

SIR,-In addition to the seven cases reported by Dr D F Rosenthal and others (24 July, p 209) 13 other cases of this syndrome have been reported in your correspondence columns. Four patients had abnormal liver function tests and two of these had mild jaundice. Two others had associated hypercalcaemia. I report another example which was interesting.

A woman aged 35 had bilateral hilar lymphadenopathy and a negative Mantoux test in 1972 . The infiltration had been present for some time because her serum electrophoresis was then normal. Her father had pulmonary tuberculosis and therefore she was considered to have sarcoidosis. Three years earlier she had had generalised arthralgia and probably had transient hyperthyroidism. A year ago she started to lose weight and had intermittent diarrhoea. Her symptoms worsened and she began to have vomiting attacks on 2 August 1976. Her serum thyroxine was then $164 \mathrm{nmol} / 1 \quad(12.3 \mu \mathrm{g} / 100 \mathrm{ml})$. She had hyperthyroidism and her serum thyroxine was 244 $\mathrm{nmol} / 1(19 \mu \mathrm{g} / 100 \mathrm{ml})$ when I saw her for the first time in September. She therefore probably has sarcoid hyperthyroidism. ${ }^{1}$

The unusual cases of this syndrome with liver involvement may have had undiagnosed sarcoidosis.

\section{St Luke's Hospital,}

' Karlish, A J, and MacGregor, G A, Lancet, 1970, 2,
330 .

G A MACGREGor

\section{Laxative effect of All-Bran}

SIR,-We were surprised by your expert's insistence (12 June, p 1461;24 July, p 236) that All-Bran is more effective than raw, unprocessed millers' bran. We know of no evidence to support this statement. We have carried out a controlled trial of All-Bran and uncooked miller's bran, given alternately and in equivalent amounts to 10 healthy subjects. At the commonly given "dose" of $20 \mathrm{~g}$ per day raw bran of the kind used in the manufacture of All-Bran significantly increased dry stool weight and shortened intestinal transit time. All-Bran itself had no significant effect when given in the fibre-equivalent "dose" of $22 \mathrm{~g}$ per day. There was, however, a trend in the same direction and doubtless a significant effect would have occurred if All-Bran had been given in larger amounts-a standard helping of this breakfast cereal is probably $30-40 \mathrm{~g}$.

Nevertheless, our findings suggest that the cooking-malting process reduces the laxative effect of wheat bran and that, weight for weight, raw bran is more effective than bran breakfast cereals. In practice the latter may be easier to take in effective amounts because of their greater palatability.

J B WYMAN

K W HEATON

A P MANNING

A C B WICKS

Department of Medicine,

Bristol Royal Infirmary,

Bristol

${ }^{1}$ Wyman, J $\underset{\text { Nutrition. }}{\mathrm{B}, \text { et al, }}$, American fournal of Clinical

\section{Postoperative pain}

SIR,-I very much enjoyed your leading article on this subject (18 September, $p$ 664) but would suggest there was a notable omission as no mention was made of the use of longacting local anaesthetics.

During my general surgical training I used locally instilled bupivicaine $(0.5 \%$ plain $)$ into herniorrhaphy wounds during closure with good relief of pain for up to $36 \mathrm{~h}$. More recently I have been using a similar technique for certain orthopaedic operations with very gratifying results. ${ }^{1}$ Our anaesthetic colleagues have also been using total lower limb blocks, administered under the anaesthetic for the operation, with good symptomatic pain relief for up to $24 \mathrm{~h}$ postoperatively.

The use of the "indwelling epidural cannula" for the relief of both post-thoracotomy and post-trauma chest pain is now also well established.

JOHN DINLEY

Accident Service,

Radcliffe Infirmary,

Dinley, J, and Dickson, $\mathrm{R}$ A, fournal of Bone and foint Surgery, 1976, 58B, 356.

\section{Oestrogens for menopausal flushing}

SIR,-We are pleased that Mr E R Broadhurst (18th September, p 697) referred to our article $^{1}$ which questioned the rationale and efficacy of oestrogen therapy in menopausal flushing. We wonder if Professor A I Klopper would amplify several points mentioned in his original article (14 August, p 414) and in his subsequent letter (18 September, p 697)?

He says that "depending on which evidence you accept" the response of hot flushes to oestrogen "can be clearly distinguished from a placebo effect." We have been unable to find any double-blind cross-over studies which show that oestrogen is significantly better than placebo. Does Professor Klopper have any information that we have overlooked?

We do not agree that a flush count is an objective way of evaluating the effect of treatment. Hot flushes are subjective. However, there are associated objective components which include alterations in skin temperature and the other changes mentioned in our article.

Professor Klopper says that it is not a question of whether oestrogens should be 